Luczyk Robert, Derylo Karolina, Luczyk Marta, Wawryniuk Agnieszka, Sikora Kamil. Stress level and ways of coping with stress in a group of patients with unstable coronary heart disease. Journal of Education, Health and Sport. 2021;11(6):164-169. eISSN 23918306. DOI http://dx.doi.org/10.12775/JEHS.2021.11.06.017

https://apcz.umk.pl/czasopisma/index.php/JEHS/article/view/JEHS.2021.11.06.017

https://zenodo.org/record/5037628

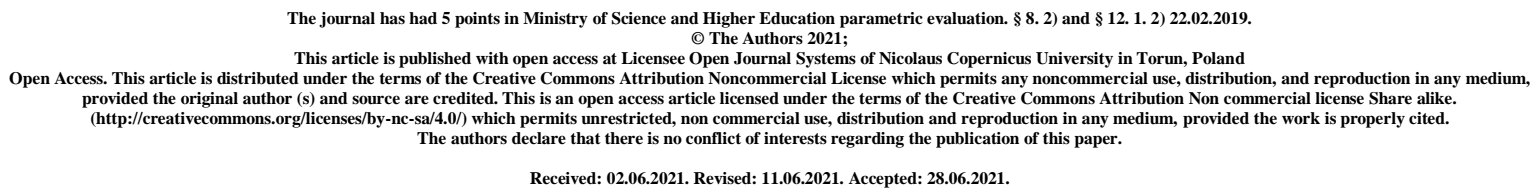

\title{
Stress level and ways of coping with stress in a group of patients with unstable coronary heart disease
}

\author{
Robert Jan Luczyk ${ }^{1}$, Karolina Deryło ${ }^{4}$, Marta Luczyk ${ }^{2}$, Agnieszka Wawryniuk ${ }^{1}$, \\ Kamil Sikora ${ }^{3}$ \\ ${ }^{1}$ Institute of Health Sciences, Faculty of Medical Sciences and Health Sciences, \\ Siedlce University of Natural Sciences and Humanities \\ ${ }^{2}$ Department of Oncology, Department of Oncology and Environmental Health Care, \\ Faculty of Health Sciences, Medical University of Lublin \\ ${ }^{3}$ Chair of Internal Medicine and Department of Internal Medicine in Nursing, \\ Faculty of Health Sciences, Medical University of Lublin \\ ${ }^{4}$ Graduate of the Faculty of Health Sciences, Medical University of Lublin
}

\section{Summary}

Introduction. Cardiovascular diseases still remain at the forefront of society's most important health problem and are one of the leading causes of death.

Purpose of research. The aim of this study is to assess the degree of coping with stress in a group of patients treated for unstable angina.

Material and methods. The research was conducted on 01.09.2019-01.03.2020. The size of the study group was 100 people, $45 \%$ of whom were women, $55 \%$ were men. People with diagnosed unstable angina took part in the study. The following research tools were used in this work to gather the necessary information: - Self-study report - contains 12 questions in the area of sociodemographic information, current disease and available support. - MiniCOPE - Inventory for Measuring Coping With Stress. • PSS-10 - Perceived Stress Scale. The above research tools made it possible to collect information on the sociodemographic data of the respondents, the degree of coping with stress and the scale of perceived stress.

Conclusions. Younger people more often than older people focused on actively coping with stress. People in relationships coped with stress to a greater extent than single people and focused on development. Patients who remain professionally active cope better with a stressful situation than those on disability or retirement. 
People after surgical procedures were more planning-oriented than those treated with pharmacological treatment. The support of family and friends has a positive effect on coping with stress in patients with unstable angina.

Key words: stress, ischemic heart disease.

\section{Introduction}

Unstable angina is also called unstable angina. It is a clinical condition between stable angina and acute myocardial infarction. It is a different form of ischemic heart disease, which in an exacerbation is called an acute coronary syndrome. Cardiovascular diseases are still at the forefront of the most common diseases in the population, but also one of the most important public health problems. Despite the dynamic development of medical sciences and better and better treatment methods, they are one of the main causes of mortality. Together with cancer, they account for over $70 \%$ of deaths. [1,2]

Stress is an inseparable part of everyone's life. For some people it is a motivational stimulus, and for others it is a source of constant upset. When trying to define the concept of stress, you should look at it holistically. This term can be considered from many points: psychological, medical, sociological or physiological. From a medical point of view, stress is a disturbance of homeostasis, that is, the balance of the body's functions due to the influence of external or psychological factors. In psychological terms, inspired by Sely's definition, stress is a physiological response of the organism to stimuli of external and internal origin. $[3,4,5]$

\section{Objective of the work}

The aim of this study is to assess the degree of coping with stress in a group of patients treated for unstable angina.

\section{Material and methods}

The research was conducted on 01.09.2019 - 01.03.2020. The size of the study group was 100 people, $45 \%$ of whom were women, $55 \%$ were men. People with diagnosed unstable angina took part in the study. The following research tools were used in this work to gather the necessary information: - Self-study report - contains 12 questions in the area of sociodemographic information, current disease and available support. - Mini-COPE Inventory for Measuring Coping With Stress. - PSS-10 - Perceived Stress Scale. The above research tools made it possible to collect information on the sociodemographic data of the respondents, the degree of coping with stress and the scale of perceived stress. In order to perform statistical analyzes, the SPSS Statistics version 25 was used. The level of $\alpha<0.05$ was adopted as statistically significant. The description of the results obtained by the respondents was made using means, confidence intervals, standard deviations, minimum, maximum, skewness and kurtosis coefficients, percentage distributions and numbers, as well as the Kolmogorowa - Smirnov distribution normality tests. Group comparisons were made using the multivariate ANOVA. Due to the small size of the subgroups, in the case of an attempt to examine the interactions between factors, only the main effect of the factors on the analyzed explained variable was verified. 
The normality of the distribution of residuals was verified on the basis of the K-S tests, and the analysis of skewness and kurtosis coefficients as well as histograms. The homogeneity of variance between the groups was tested on the basis of Leven's tests. The partial coefficient eta square was used to describe the effect size for the calculated differences. It was interpreted as follows eta $2=0.01$ small effect; eta $2=0.06$

\section{Results}

The research was conducted on 01.09.2019 - 01.03.2020. The size of the study group was 100 people, $45 \%$ of whom were women, $55 \%$ were men. People with diagnosed unstable angina took part in the study. The subjects were patients at the Provincial Specialist Hospital of Cardinal Stefan Wyszyński in Lublin and the Independent Public Clinical Hospital No. 4 in Lublin.

Most of the respondents were between 50 and 79 years of age. $11 \%$ of respondents had less than 50 years of age, while $10 \%$ were above 79 . Most of the respondents came from the city $(73 \%)$ than from the countryside $(27 \%)$, lived with their family $(68 \%)$, was in a relationship with another person $(57 \%)$ and was retired (50\%). The smallest fraction were the unemployed (4\%). They live alone (32\%) due to their social status (15\%), and have primary education due to their education $(11 \%)$.

The largest number were people aged 60 to 69 (33\%), while the smallest were people over $80(10 \%)$. The remaining respondents accounted for $11 \%$ of people under $50,22 \%$ of people aged $70-79$ and $24 \%$ of people between 50 and 59 years of age.

\section{The level of stress and coping with it by the respondents}

The average PSS score was 6.25 [95\% CI $(5.87,6.63)]$ with a standard deviation of 1.90. The minimum number of points obtained by the respondents was within 2 sten, and the maximum 10. The group of respondents showed a slightly elevated level of stress, although still within the moderate limits.

Table 1. Strategies of coping with stress by the respondents

\begin{tabular}{|c|c|c|c|c|c|c|c|}
\hline \multirow[t]{2}{*}{ A strategy for coping with stress } & \multirow[t]{2}{*}{$\mathbf{M}$} & \multicolumn{2}{|c|}{$\begin{array}{c}\text { Confidence } \\
\text { interval } \\
95 \%\end{array}$} & \multirow[t]{2}{*}{ Me } & \multirow[t]{2}{*}{ SD } & \multirow[t]{2}{*}{$\min$} & \multirow[t]{2}{*}{$\max$} \\
\hline & & $\begin{array}{c}\text { Lower } \\
\text { limit }\end{array}$ & $\begin{array}{c}\text { Upper } \\
\text { limit }\end{array}$ & & & & \\
\hline Active coping & 5,67 & 5,39 & 5,96 & 6 & 1,52 & 1 & 8 \\
\hline Planning & 5,13 & 4,76 & 5,52 & 6 & 1,94 & 1 & 8 \\
\hline Search for instrumental support & 5,33 & 4,95 & 5,72 & 5 & 1,88 & 2 & 9 \\
\hline
\end{tabular}




\begin{tabular}{|c|c|c|c|c|c|c|c|}
\hline Seeking emotional support & 5,34 & 5,05 & 5,63 & 5,5 & 1,51 & 2 & 8 \\
\hline Blame & 6,38 & 5,90 & 6,86 & 6 & 2,44 & 2 & 10 \\
\hline Turn to religion & 7,01 & 6,59 & 7,48 & 7 & 2,26 & 4 & 10 \\
\hline Positive reevaluation & 5,62 & 5,29 & 5,95 & 6 & 1,70 & 1 & 9 \\
\hline Discharge & 6,42 & 5,99 & 6,88 & 7 & 2,28 & 3 & 10 \\
\hline Acceptance & 5,38 & 5,02 & 5,76 & 6 & 1,88 & 1 & 9 \\
\hline Denial & 6,91 & 6,49 & 7,36 & 7 & 2,21 & 4 & 10 \\
\hline Doing something else & 6,15 & 5,79 & 6,53 & 6 & 1,88 & 2 & 9 \\
\hline Cessation of activities & 6,75 & 6,31 & 7,17 & 7 & 2,07 & 4 & 10 \\
\hline
\end{tabular}

$M$ - Average; Me - median; SD - standard deviation

The results of the respondents were within the limits of moderate results on all scales except for the scale of turning to religion. In this case, the estimated $95 \%$ confidence interval for the mean in this case exceeded the range of moderate results and was within the limits of increased results ( 7 sten).

The respondents used the strategies of active coping, planning, seeking instrumental and emotional support with moderate intensity against the background of the "population", they blamed themselves, positively re-evaluated themselves, vented their emotions, accepted the situation, denied it, dealt with something else, gave up activities, used alcohol and reacted sense of humor, but more often than the average person from the standardization test, they turned to religion. 
Table 2. Distributions of raw results obtained in the PSS and mini COPE scales

\begin{tabular}{|c|c|c|c|c|c|c|c|c|c|}
\hline A strategy for coping with stress & $\mathbf{M}$ & Me & SD & $\begin{array}{c}\text { SKE } \\
\text { W }\end{array}$ & $\begin{array}{c}\text { KUR } \\
\text { T }\end{array}$ & $\min$ & $\max$ & K-S & $\mathbf{P}$ \\
\hline A sense of stress & $\begin{array}{c}18,8 \\
5\end{array}$ & 19 & 6,34 & $-0,173$ & $\begin{array}{c}- \\
0,243\end{array}$ & 1 & 32 & 0,07 & 0,200 \\
\hline Active coping & 1,91 & 2 & 0,63 & $-0,316$ & 0,072 & 0 & 3 & 0,20 & 0,000 \\
\hline Planning & 1,71 & 2 & 0,77 & $-0,350$ & $\begin{array}{c}- \\
0,459\end{array}$ & 0 & 3 & 0,23 & 0,000 \\
\hline Search for instrumental support & 1,58 & 1,5 & 0,80 & $-0,067$ & $\begin{array}{c}- \\
0,492\end{array}$ & 0 & 3 & 0,15 & 0,000 \\
\hline Seeking emotional support & 1,67 & 1,75 & 0,76 & $-0,098$ & $\begin{array}{c}- \\
0,573\end{array}$ & 0 & 3 & 0,17 & 0,000 \\
\hline Blame & 1,55 & 1,5 & 0,91 & 0,017 & $\begin{array}{c}- \\
0,859\end{array}$ & 0 & 3 & 0,12 & 0,001 \\
\hline Turn to religion & 1,51 & 1,5 & 1,13 & $-0,029$ & $\begin{array}{c}- \\
1,505\end{array}$ & 0 & 3 & 0,15 & 0,000 \\
\hline Positive reevaluation & 1,74 & 2 & 0,65 & $-0,223$ & $\begin{array}{c}- \\
0,025\end{array}$ & 0 & 3 & 0,20 & 0,000 \\
\hline Discharge & 1,36 & 1,5 & 0,82 & $-0,090$ & $\begin{array}{c}- \\
0,927\end{array}$ & 0 & 3 & 0,13 & 0,000 \\
\hline Acceptance & 1,75 & 2 & 0,71 & $-0,663$ & 0,443 & 0 & 3 & 0,24 & 0,000 \\
\hline Denial & 1,19 & 1 & 0,96 & 0,373 & $\begin{array}{c}- \\
0,976\end{array}$ & 0 & 3 & 0,14 & 0,000 \\
\hline Doing something else & 1,62 & 1,5 & 0,86 & $-0,219$ & $\begin{array}{c}- \\
0,761\end{array}$ & 0 & 3 & 0,15 & 0,000 \\
\hline Cessation of activities & 0,94 & 1 & 0,67 & 0,325 & $\begin{array}{c}- \\
0,529\end{array}$ & 0 & 2,5 & 0,18 & 0,000 \\
\hline Taking alcohol & 0,33 & 0 & 0,60 & 1,806 & 2,429 & 0 & 2,5 & 0,43 & 0,000 \\
\hline Sense of humor & 0,90 & 1 & 0,62 & 0,690 & 0,000 & 0 & 2,5 & 0,22 & 0,000 \\
\hline
\end{tabular}

$M$ - Average; Me - median; SD - standard deviation; SKEW - skewness coefficient; KURT -

kurtosis coefficient; $K$-S - Kolmogorwa-Smirnov test result; $p$ - test probability 


\section{Conclusions}

1. Patients diagnosed with unstable angina feel a moderate level of stress.

2. In the group of respondents, women much more often than men sought emotional support.

3. Women much more often than men turned to religion.

4. Patients with unstable angina are much more common than the average person from the normalization group they turned to religion.

5. Younger people more often than older people focused on actively coping with stress.

6. People in relationships coped with stress to a greater extent than single people and focused on development.

7. Male respondents, respondents under 49 years of age and people living in the countryside, used alcohol and / or other psychoactive substances in a stressful situation much more often than other respondents.

8. Professionally active patients cope better with a stressful situation than people on disability or retirement.

9. People after surgical procedures were more planning-oriented than those treated with pharmacological treatment.

10. Support from family and friends has a positive effect on coping with stress in patients with unstable angina. 11. Patients with comorbidities rarely responded to stress by discharging emotions.

\section{Bibliography}

1. Grech E.D., Ramsdale D.R.: Acute coronary syndrome: unstable angina and non-ST segment elevation myocardial infarction. British Med. J. 326, 2003.

2. Mandecki T.: Kardiologia. Wydawnictwo Lekarskie PZWL, Warszawa 2005.

3. Grygorczuk A.: Pojęcie stresu $w$ medycynie i psychologii. W: Psychiatria tom 5, nr 3, s.111-115. Via Medica 2008.

4. Jakubowska-Winecka A., Włodarczyk D.: Psychologia $w$ praktyce medycznej. Wydawnictwo Lekarskie PZWL, Warszawa 2007.

5. Kaczmarska A., Curyło-Sikora P.: Problematyka stresu - przeglad koncepcji. Hygeia Public Health 2016, 51(4): 317-321. 